\title{
JUURNAL.RU
}

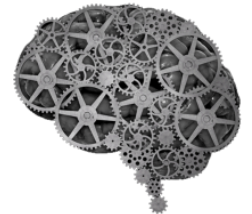

COMPANY GROUP "INTELLEKT"

Лёгенький Е.А. Гомельский государственный технический университет имени П.О. Сухого Гомель, Республика Беларусь

doi: 10.18411/lj2016-5-2-14

\section{Сравнительный анализ идеальной нагрузочной характеристики тахогенератора с экспериментальной на лабораторном стенде "технологические датчики"}

\section{Аннотация}

В статье рассматривается специфика объяснения и понимания в учебном процессе, раскрывается их взаимодополнительность, обосновывается необходимость обеспечения их тесной взаимосвязи посредством организации образования на основе постоянного творческого диалога между преподавателями и студентами.

Ключевые слова: объяснение, понимание, диалог, организация учебного процесса

\section{Annotation}

The article considers explanation and understanding phenomena in education as a whole two-way communication and proves their correlation and complementarity. It also contemplates educational process attributes providing it to be a constructive dialogue between lecturer and students.

Keywords: explanation, understanding, dialogue, organizing of educational process 
Преподаватели профессионально имеют дело с феноменами объяснения и понимания, вне зависимости от их специализации и преподаваемых учебных дисциплин. Однако специфика и логика образовательной деятельности ведут к тому, что данные явления зачастую воспринимаются в качестве достаточно самостоятельных сторон или аспектов учебного процесса. Отношение между объяснением и пониманием иногда трактуют в соответствии с духом институционально закрепленных ролей «учителя» и «ученика». Указанная функционально-ролевая специализация в учебном процессе вызывает соблазн разрубить гордиев узел проблемы однозначным решением: задача «учителя» «объяснять», а «ученика» - «понимать».

Хотя подобная трактовка не лишена определенных оснований, различие процессов объяснения и понимания, а также основа их взаимосвязи лежит значительно глубже однозначного распределения ролей в учебном процессе. Трудноуловимая грань между ними пролегает внутри каждого человека, будь то учитель или ученик. Объяснение и понимание выступают в качестве двух фундаментальных свойств сознательного субъекта, с помощью которых он осваивает - познает и организует - внешний мир. Именно поэтому «объяснение» и «понимание» являются важнейшими категориями для современной методологии науки и философии.

Не преследуя цели сколько-нибудь развернутого рассмотрения фундаментальной проблемы взаимосвязи между объяснением и пониманием в человеческом познании и культуре в целом, считаю целесообразным отметить в самом общем виде ряд их важных отличий друг от друга, а также их своеобразную взаимодополнительность. Это позволит раскрыть важные аспекты данной проблемы в области обучения и образовательного процесса в целом.

Под объяснением обычно понимают раскрытие связей между неизвестными еще явлениями и процессами и другими - уже известными и объясненными. Процедура объяснения необходима, когда требуется установить связь неизвестного объекта с явлениями и процессами, которые его причинно 
обусловливают, являются более общими и фундаментальными, что позволяет подвести объект объяснения под действие уже установленных закономерностей действительности. Объяснение выступает как раскрытие сущности изучаемого объекта посредством постижения существенных связей и отношений, выражающих закон его развития.

Важно подчеркнуть, что объяснение базируется на установлении причин, условий и факторов, которые обусловливают существенные черты изучаемого объекта, - в определенной системе теоретического знания. Поэтому основанием для объяснения служат общие категориальные схемы, отражающие различные связи и зависимости. В логике объяснение связывают, прежде всего, с процедурой выведения (дедукцией) объясняющих положений из уже установленных и доказанных утверждений. Иными словами, объяснение основано на использовании рациональных логических приемов и процедур: сравнения, описания, аналогии, указания на причины, составления модели и других. Именно осознание особого места объектов объяснения в некоторой системе взаимосвязей и законов позволяет человеку эффективно действовать в познавательной и практической сфере.

Понимание с самого начала было противопоставлено объяснению как процедуре, подводящей единичное и особенное под всеобщее на основе установления причинно-следственных зависимостей. Понимание связывали с особым методом познания явлений культуры, постижением природы индивидуального на основе специфических процедур «вживания» и «вчувствования» субъекта в объект, имеющих преимущественно интуитивный характер. Понимание приобретало характер не только способа познания человеком мира, но и способа бытия человека в мире, благодаря которому только и становится возможным сам данный метод познания. Следовательно, понимание как особый процесс освоения мира непосредственно соотносит постижение объекта с самим субъектом познания: с жизнью человека, с его 
способностью к приписыванию значений и стремлением к поиску лично значимого смысла.

Дальнейшие исследования объяснения и понимания в качестве особых способов освоения действительности привели к убедительным выводам об их тесной взаимосвязи и взаимообусловленности. Человеку недостаточно иметь объективную информацию, знание об объекте. Они должны иметь для него определенный смысл. Объект должен вписаться в существующую картину мира субъекта. А поскольку жизнь человека протекает в сообществе людей, его картина мира обусловлена коллективными представлениями, социально сконструирована. Коллективное приписывание смыслов и структурирование опыта, проистекающее из самого человеческого бытия, становится основой для рациональных объяснительных схем. Понимание обусловливает процедуру объяснения. В свою очередь, рациональное объяснение и структурирование знаний ведет к развитию и объективированию нового опыта социума в устойчивых формах понимания действительности, приписывающих событиям смысл и значение. Рациональные процедуры объяснения служат углублению понимания человеком самого себя и мира в целом.

Глубинная взаимосвязь и взаимодополнительность объяснения и понимания, представляющих собой универсальные механизмы освоения действительности, находит свое выражение во всех областях деятельности, в том числе - в области образования и обучения. Поэтому в качестве главного вывода, который отсюда следует, может служить утверждение необходимости обеспечения единства объяснения и понимания в учебном процессе.

Однако вполне очевидно, что эта громкая констатация в большей степени является образом желаемого, чем характеристикой реального положения дел. Только в идеале можно достичь одинаково высоких ступеней знания и понимания всеми студентами и по всем предметам. В реальности доминирующей ориентацией учебного процесса является объяснение как 
передача определенной суммы знаний в виде объяснительных схем, понятий, категорий, законов, указаний на условия и границы их действия.

Зачастую эти знания специально сжаты и модифицированы, в них опущены некоторые посредствующие звенья, которые в определенной степени нарушают логико-дедуктивный вывод и тем самым затрудняют понимание материала студентами. Главным образом это делается в целях увеличения общего объема передаваемых знаний. $\mathrm{B}$ этих условиях мастерство преподавателя заключается в методически правильном построении учебного процесса, который не исключал бы активности студентов, способных самостоятельно восполнить логические разрывы и пропуски в процессе объяснения.

Вместе с тем, приходится констатировать, что процедура понимания перемещается из сферы диалога «учителя» и «ученика» в сферу самостоятельной работы обучаемых. Сокращается непосредственное влияние со стороны преподавателя на область понимания студентами учебного материала, что в значительной степени снижает эффективность процесса обучения.

Практика преподавания уже попыталась дать ответ на вопрос, как в подобных условиях добиваться понимания студентами учебного материала. Речь идет о, так называемых, активных формах обучения. К ним относят учебные и деловые игры, компьютерные симуляции, дискуссии по проблемам, мозговой штурм, использование методики case-study, но к ним следует отнести также и подготовку докладов и письменных работ по темам курса с постановкой задачи выработать личный аргументированный взгляд на проблему.

Широкое использование указанных форм в учебном процессе способствует обеспечению тесного единства между усвоением готовых знаний в процессе объяснения и процессом их понимания. Именно данное единство может служить надежной преградой на пути снижения эффективности учебного процесса, когда в итоге обучения студенты приобретают лишь сумму знаний и 
навыков, далеко не в полной мере понятых, усвоенных и готовых к операциональному использованию.

К сожалению, подобный результат образовательного процесса далеко не редкость. Вполне очевидно также, что активные формы обучения не могут служить полноценной заменой реальной практики профессиональной деятельности. Однако мудрость жизни заключается именно в том, что она предоставляет возможности для развития скрытых или непроявившихся потенций и способностей. Как только выпускники становятся молодыми специалистами и в реальном деле начинают совершенствовать свой профессионализм, у них появляются условия для превращения некогда мертвой суммы сведений в полноценное знание об объекте своей деятельности. Они обретают понимание своего места и роли в процессе освоения действительности. Дальнейшее совершенствование и обновление специальных профессиональных знаний и навыков происходит в ходе последующей переподготовки и повышения квалификации.

Однако сравнительно благополучно проблема разрешается лишь применительно к специальным профессиональным знаниям, которые быстро обретают твердую опору в практической деятельности. С непрофильными или общеобразовательными дисциплинами дело обстоит несколько сложнее. Готовые знания, не включенные в активный процесс постоянного субъективного переосмысления и переживания в ходе профессиональной деятельности, быстро утрачиваются.

Вместе с тем, именно общеобразовательные и гуманитарные дисциплины (история, философия, социология, культурология, этика, право, политология и другие) формируют личность человека, определяют его кругозор, мировоззрение, способность критически мыслить и самостоятельно оценивать действительность. Нет необходимости доказывать, насколько данные качества важны в современном мире для специалистов любого профиля и квалификации. Более того, они совершенно незаменимы при продвижении по службе, росте 
карьеры, достижении высших постов, уровней управления, а также при смене профессии, области деятельности, при работе в смежных областях.

Поскольку послевузовская профессиональная переподготовка и повышение квалификации направлены, главным образом, на совершенствование специальных знаний, остается один выход: создавать полноценную основу для дальнейшего самообразования в области общеобразовательных и гуманитарных дисциплин. Сумма готовых знаний без их личностного осмысления и понимания не может составить такую основу.

Поэтому именно при преподавании дисциплин гуманитарного цикла проблема взаимосвязи между объяснением и пониманием обретает особую остроту. Сегодня преподаватели вынуждены решать сложнейшую задачу: в условиях сокращения учебных часов на гуманитарные дисциплины необходимо совместить усвоение студентами определенного набора знаний (в виде сведений, дефиниций, обобщений и выводов) с развитием их умения формировать свое сознательное личностное отношение к этим знаниям, развитием способности к их критическому переосмыслению, установлению критериев оценки явлений и процессов, а также продуцированию собственных подходов к анализу и решению проблем.

Вполне очевидно, что решение этой задачи предполагает значительное увеличение нагрузки на преподавателей, связанной с постоянной готовностью работать в режиме активного диалога и индивидуального подхода к студентам. Нередко это приводит к ситуации, когда преподаватели осуществляют такой подход к обучению, затрачивая большую энергию, делясь своими знаниями и опытом со своими студентами, за рамками официальных учебных планов, фактически факультативно и бескорыстно. Сделать общим правилом подобную самоотверженность представляется невозможным. Гораздо чаще преподаватели в общении со студентами вынуждены сосредоточиваться на выполнении многочисленных (и все увеличивающихся) формализованных требований к 
реализации учебных программ. Наметилась крайне опасная тенденция превращения преподавателя в бюрократа от образования.

Долгие годы реформирования постсоветского образования в центре внимания находилась задача повышения активности обучаемых в учебном процессе. Настало время обратить внимание на другую сторону образовательного процесса как диалога между «учеником» и «учителем» фигуру преподавателя. Без его участия в учебном процессе образование превращается в самообразование. Само по себе, самообразование - это прекрасно, однако далеко не все обучающиеся к этому способны. Учебный процесс предполагает умелое сочетание образовательной деятельности преподавателей с организованным при их активном участии процессом самообразования студентов. Изъять из этого целостного процесса преподавателя, - сократив учебные часы, перегрузив его выполнением формальных правил, отчетностью, контролем конечного результата - означает разрушение его диалога с обучающимися. Предоставленные самим себе, студенты не всегда способны справляться с поставленными задачами. В результате под угрозой оказывается не только понимание полученных знаний, но и сам процесс полноценного усвоения знаний. Большое количество творческих самостоятельных заданий у современных студентов не ведет автоматически к поставленным целям. Напротив, перегруженные, как и преподаватели, студенты прибегают к любым возможным способам выполнения работ, включая плагиат, заказные курсовые и выпускные работы. В ответ усиливается контроль, формальные требования, развивается система «Антиплагиат». Представляется, что это порочный круг. Разорвать его можно, лишь создавая условия для творческой деятельности и постоянного диалога в образовательном процессе, как для студентов, так и для преподавателей. Совершенствование современного образования должно учитывать эту безусловную потребность, чтобы организационные формы не довлели над его содержанием и целью, чтобы решение сиюминутных задач не растоптало ростки 
будущего. 


\section{Литература:}

1. Залевский Г.В. Объяснение и понимание как методы наук о психике // Вестник Томского государственного университета. Серия «Психология». Март 2005. №286. - Томск, 2005. С .3-14.

2. Опыт преподавания профессорско-преподавательским составом дисциплин кафедры политологии: сборник научных статей / под ред. Я.А. Пляйса, А.М. Ястремского. - М.: Финансовый университет, 2011. - 100 с.

3. Теоретические и методические проблемы инновационной системы образования в Финансовой академии при Правительстве Российской Федерации: Монография. - М.: Финакадемия, 2008. - 276 с.

4. Хаджаров М.Х. Объяснение и понимание в научном познании: коррелятивные отношения // Международный научно-исследовательский журнал. Выпуск Октябрь 2012. Философские науки. [Электронный ресурс]

- Режим доступа: http://research-journal.org/featured/philosophy/obyasnenie-iponimanie-v-nauchnom-poznanii-korrelyativnye-otnosheniya/ обращения 07.04.2015). 